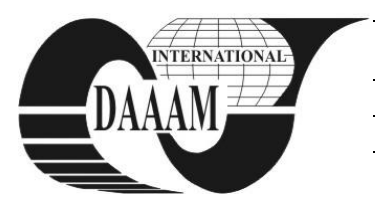

Annals of DAAAM for 2012 \& Proceedings of the 23rd International DAAAM Symposium, Volume 23, No.1, ISSN 2304-1382 ISBN 978-3-901509-91-9, CDROM version, Ed. B. Katalinic, Published by DAAAM International, Vienna, Austria, EU, 2012 Make Harmony between Technology and Nature, and Your Mind will Fly Free as a Bird Annals \& Proceedings of DAAAM International 2012

\title{
GENETIC ALGORITHM BASED OPTIMIZATION DURING WIRE ELECTRIC DISCHARGE MACHINING OF METAL MATRIX COMPOSITE
}

\author{
SHANDILYA, P[ragya] \& JAIN, P[ramod] K[umar]
}

\begin{abstract}
The present work is focused on optimization of process parameters during wire electric discharge machining (WEDM) of metal matrix composites (MMCs). Response surface methodology (RSM) and genetic algorithm (GA) integrated with each other to optimize the process parameters. Four WEDM parameters namely servo voltage, pulse-on time, pulse-off time and wire feed rate were varied to study their effect on the quality of cut in $\mathrm{SiC}_{\mathrm{p}} / 6061 \mathrm{Al}$ MMC using surface roughness as response parameter. The relationship between surface roughness and machining parameters has been developed by using RSM. The mathematical model thus than developed was then employed on GA to optimized the process parameters.

Keywords: Wire electric discharge machining (WEDM), Metal matrix composite $(M M C)$, Genetic algorithm (GA), Response surface methodology (RSM)
\end{abstract}

\section{INTRODUCTION}

Wire electric discharge machining (WEDM) is a well-established machining option for manufacturing geometrically complex and hard material parts that are extremely difficult to machine by conventional machining process [1]. WEDM is a thermo-electric process in which material is eroded from the work-piece by a series of discrete sparks between the work-piece and the wire electrode (tool) separated by a thin film of dielectric fluid which is continuously forced in to the machining zone to flush away the eroded particles. The movement of the wire is controlled numerically to achieve the desired three-dimensional shape and accuracy for the workpiece (as shown in Fig. 1).

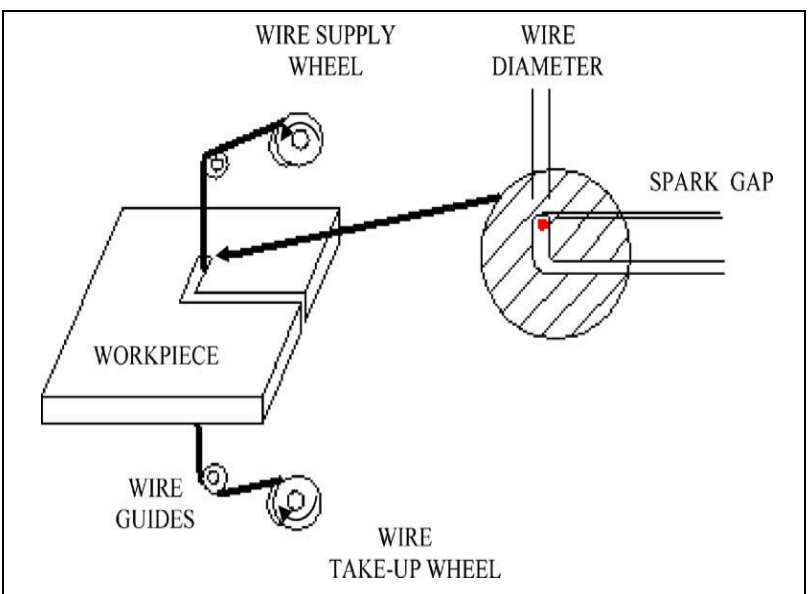

Fig. 1. Detail of WEDM cutting gap

Dimensional and geometrical accuracies of the cut profile depend on the accuracy of wire control mechanism. Selection of process parameters is crucial to the overall performance of the WEDM process. Among the different machining processes, WEDM process considered as an effective and economical process during machining of MMCs [2]. Lot of research work has been done on WEDM, but very few investigations have been done on WEDM of MMCs [3]. In the most recent work, Shandilya et al. [4] studied the effect of input process parameters on surface roughness during WEDM of $\mathrm{SiC}_{\mathrm{p}} / 6061 \mathrm{Al} \mathrm{MMC}$. Results show that, voltage is the most significant parameter on surface roughness, where as pulse-on time and pulse-off time have less significant effect on surface roughness.

At present WEDM parameter selection is still one experience process in the industry. In some cases, selected parameters are conservative and far from the optimum, and at the same time selecting optimization parameters requires many costly and time consuming experiments [5]. Many researchers tried to optimize the machining performance by adapting different optimization techniques. Response surface methodology (RSM) is an effective technique in carrying out the analysis of experiments with the least experimental efforts and subsequently to develop suitable mathematical models of responses [6]. Genetic algorithm (GA) possesses advantages that do not require any gradient information and inherent parallelism in searching the design space, thus making it a robust adaptive optimization technique [7]. Kuriakose and Shunmugam [8] presented a multiple regression model to represent the relationship between input and output variables and multi-objective optimization method based on a Non-Dominated Sorting Genetic Algorithm to optimize Wire-EDM process.

In the present work RSM and GA are used together to establish parameter optimization model. RSM model has been established to represent the relationship between surface roughness and input variables (voltage, pulse-on time, pulse-off time and wire feed rate). GA has been used to obtain an optimal combination of parameters.

\section{EXPERIMENTAL METHOD AND TEST CONDITIONS}

The experiments were conducted on the ECOCUT WEDM Machine (Electronica India Make) on 6061 aluminum based MMC work pieces of rectangular shape (6.0 mm thickness), made by stir casting having $10 \% \mathrm{SiC}$ particles (by weight) as reinforcement. The chemical 
composition of Al 6061 was determined by energy dispersive X-Ray spectroscopy (EDS). Table 1 shows the chemical composition of the matrix of the MMC used in this study.

As four input process parameters namely servo voltage $(\mathrm{SV})$, pulse-on time $\left(\mathrm{T}_{\mathrm{ON}}\right)$, pulse-off time $\left(\mathrm{T}_{\mathrm{OFF}}\right)$ and wire feed rate (WF) affect WEDM process performance and hence were chosen as input variables to investigate their effects on surface roughness during machining of $\mathrm{SiC}_{\mathrm{p}} / 6061$ aluminum $\mathrm{MMC}$ as response parameters. Other details of experimental setup are given in Table 2. The ranges of input parameters were selected on the basis of literature survey, machining capability of the machine and preliminary experiments conducted by using one-variable-at-a-time approach as shown in Table 3 [9]. The response parameter surface roughness was measured by using Scanning Probe Microscope (Model NTEGRA, made in Russia).

\begin{tabular}{|c|c|}
\hline Element & Composition $(\mathbf{w t} \%)$ \\
\hline $\mathrm{Al}$ & 95.83 \\
\hline $\mathrm{Si}$ & 0.68 \\
\hline $\mathrm{Mg}$ & 1.20 \\
\hline $\mathrm{Cu}$ & 0.61 \\
\hline $\mathrm{Mn}$ & 0.45 \\
\hline $\mathrm{Cr}$ & 0.50 \\
\hline $\mathrm{Fe}$ & 0.27 \\
\hline $\mathrm{Ti}$ & 0.46 \\
\hline
\end{tabular}

Tab. 1. Chemical composition of Al 6061 alloy

\begin{tabular}{|c|c|}
\hline Wire & Diffused brass wire $\Phi 0.25 \mathrm{~mm}$ \\
\hline Workpiece material & $10 \% \mathrm{SiC}_{\mathrm{p}} / 6061 \mathrm{Al} \mathrm{MMC}$ \\
\hline Workpiece height & $6 \mathrm{~mm}$ \\
\hline Length of cut & $15 \mathrm{~mm}$ \\
\hline Dielectric & Deionized water \\
\hline Dielectric temperature & $20^{\circ} \mathrm{C}$ \\
\hline
\end{tabular}

Tab. 2. Experimental conditions

\begin{tabular}{|c|c|c|c|}
\hline \multirow{2}{*}{ Process parameters } & \multicolumn{3}{|c|}{ Levels } \\
\cline { 2 - 4 } & $\mathbf{- 1}$ & $\mathbf{0}$ & $\mathbf{+ 1}$ \\
\hline Voltage $(\mathrm{V})$ & 70 & 80 & 90 \\
\hline Pulse-on time $(\mu \mathrm{s})$ & 1 & 2 & 3 \\
\hline Pulse-off time $(\mu \mathrm{s})$ & 6 & 8 & 10 \\
\hline Wire feed $(\mathrm{m} / \mathrm{min})$ & 5 & 7 & 9 \\
\hline
\end{tabular}

Tab. 3. Levels of process parameters

\section{RESPONSE SURFACE METHODOLOGY}

Response surface methodology (RSM) approach is the procedure for determining the relationship between various process parameters with various machining criteria and exploring the effects of these process parameters on the coupled responses [10]. In this work also RSM is used to determine the relationship between the input process parameters of WEDM with surface roughness. In order to study the effects of WEDM parameters, on surface roughness second order polynomial response surface mathematical model developed. Commonly, the response surface is described by an equation of the form [11]:

$y=\beta o+\sum_{i=1}^{n} \beta_{i} x_{i}+\sum_{i=1}^{n} \beta_{i i} x_{i}^{2}+\sum \sum_{i<1} \beta_{i j} x_{i} x_{j}$

where, $\mathrm{y}$ is the corresponding response produced by input process parameters of WEDM and $x_{i}(1,2, \ldots .$.$) are coded$ levels of $\mathrm{S}$ quantitative process variables. The terms $\beta o$, $\beta_{i}, \beta_{i i}$ and $\beta_{i j}$ are the second order regression coefficients.

In order to study the effects of input process parameters during WEDM of $\mathrm{SiC}_{\mathrm{p}} / 6061 \mathrm{Al} \mathrm{MMC}$ on surface roughness, a second order polynomial response can be fitted as follows:

$$
\begin{gathered}
Y=\beta_{0}+\beta_{1} x_{1}+\beta_{2} x_{2}+\beta_{3} x_{3}+\beta_{4} x_{4}+ \\
\beta_{11} x_{1}^{2}+\beta_{22} x_{2}^{2}+\beta_{33} x_{3}^{2}+\beta_{44} x_{4}^{2}+\beta_{12} x_{1} x_{2}+\beta_{13} x_{1} x_{3}+ \\
\beta_{14} x_{1} x_{4}+\beta_{23} x_{2} x_{3}+\beta_{24} x_{2} x_{4}+\beta_{34} x_{3} x_{4}
\end{gathered}
$$

Where $x_{1}, x_{2}, x_{3}$ and $x_{4}$ are voltage, pulse-on time, pulse-off time and wire feed rate respectively.

\subsection{RSM based results and analysis}

The WEDM process was studied according to the Box-Behnken design (BBD) and corresponding levels and values of four input process parameters are shown in Table 3. Table 4 shows the experimental results of the 29 experiments conducted in this study along with the order, combinations and design of experiments based on the coded surfaces. The mathematical process models were established using 'Design Expert 6.0' software with an objective of determining the optimal input process parameters to achieve the desired response parameters i.e. surface roughness during $\mathrm{WEDM}$ of $\mathrm{SiC}_{\mathrm{p}} / 6061 \mathrm{Al}$ MMC.

Table 5 shows the variance analysis results of the introduced models. The associated $\mathrm{P}$ value for the model is lower than 0.05 (i.e. $\alpha=0.05$ or $95 \%$ confidence) indicating that the model is statistically significant.

\begin{tabular}{|c|c|c|c|c|c|}
\hline Exp. No. & $\begin{array}{c}\mathbf{V} \\
(\mathbf{V})\end{array}$ & $\begin{array}{c}\mathbf{T}_{\mathbf{O N}} \\
(\boldsymbol{\mu s})\end{array}$ & $\begin{array}{c}\mathbf{T}_{\mathbf{O F F}} \\
(\boldsymbol{\mu s})\end{array}$ & $\begin{array}{c}\mathbf{W F} \\
(\mathbf{m} / \mathbf{m i n})\end{array}$ & $\begin{array}{c}\mathbf{S R} \\
(\boldsymbol{\mu} \mathbf{m})\end{array}$ \\
\hline 1 & 0 & 1 & 0 & -1 & 2.3 \\
2 & -1 & 0 & 0 & -1 & 1.78 \\
3 & 0 & 0 & 1 & 1 & 2.05 \\
4 & -1 & 0 & 1 & 0 & 1.8 \\
5 & 0 & -1 & -1 & 0 & 1.92 \\
6 & 1 & 0 & 0 & -1 & 2.92 \\
7 & 1 & 0 & -1 & 0 & 2.88 \\
8 & 0 & 0 & 0 & 0 & 2.12 \\
9 & 0 & 0 & 0 & 0 & 2.02 \\
10 & 1 & 0 & 0 & 1 & 2.72 \\
11 & 0 & 0 & 1 & -1 & 2.06 \\
12 & 0 & 0 & 0 & 0 & 2.04 \\
13 & 0 & -1 & 0 & 1 & 1.95 \\
14 & 0 & 0 & 0 & 0 & 2.35 \\
15 & 0 & 1 & 0 & 1 & 2.32 \\
16 & 0 & 0 & 0 & 0 & 2.16 \\
17 & 1 & 0 & 1 & -1 & 2.86 \\
18 & 0 & 1 & -1 & -1 & 2.5 \\
19 & 0 & 0 & -1 & 1 & 2.22 \\
20 & 0 & -1 & 0 & -1 & 1.98 \\
21 & 0 & 0 & -1 & -1 & 2.54 \\
22 & 0 & -1 & 1 & 0 & 1.89 \\
23 & 1 & 1 & 0 & 0 & 3.08 \\
24 & -1 & 0 & -1 & 0 & 1.85 \\
25 & -1 & 1 & 0 & 0 & 1.87 \\
26 & -1 & 0 & 0 & 1 & 2.26 \\
27 & -1 & -1 & 0 & 0 & 1.77 \\
28 & 1 & -1 & 0 & 0 & 2.7 \\
29 & 0 & 1 & 1 & 0 & 2.26 \\
\hline & 0 & 0 & 0 & 0 \\
\hline
\end{tabular}

Tab. 4. Box-Behnken design with four input process parameters and experimental surface roughness 
It also shows the value of $\mathrm{R}^{2}$-statistic and adjusted $\mathrm{R}^{2}$-statistic.

The more $\mathrm{R}^{2}$ approaches unity, the better model fits the experimental data. For instance, the obtained value of 0.8836 for $\mathrm{R}^{2}$ in case of surface roughness implies that the model explains approximately $88.36 \%$ of the variability in surface roughness, where as $\mathrm{R}^{2}$ adjusted for the model is 0.8812 .

Table 6 presents the values of $b$ coefficients of model. Values of " Prob $>$ F" less than 0.0500 indicate model terms are significant. According to Table 6, voltage (V), pulse-on time $\left(\mathrm{T}_{\mathrm{ON}}\right)$, pulse-off time $\left(\mathrm{T}_{\mathrm{OFF}}\right)$, quadratic effect of voltage $(\mathrm{V} \times \mathrm{V})$ and interaction effect of voltage with wire feed rate $(\mathrm{V} \times \mathrm{WF})$ have significant effects on surface roughness. The other model terms for which associated $\mathrm{P}$ values are more than 0.05 and thus are nonsignificant in this case.

\begin{tabular}{|l|l|l|l|l|l|}
\hline Sourse & $\begin{array}{l}\text { Sum of } \\
\text { Square }\end{array}$ & d.f. & $\begin{array}{l}\text { Mean } \\
\text { Square }\end{array}$ & $\begin{array}{l}\text { F- } \\
\text { value }\end{array}$ & P-value \\
\hline Model & 3.18 & 14 & 0.27 & 15.84 & $<0.0001$ \\
\hline Residual & 0.24 & 14 & 0.017 & & \\
\hline Total & 4.05 & 28 & & & \\
\hline R-Squared & 0.8836 & & & & \\
\hline $\begin{array}{l}\text { Adjusted R- } \\
\text { Sqared }\end{array}$ & 0.8812 & & & & \\
\hline Standard Dev. & 0.13 & & & & \\
\hline
\end{tabular}

Tab. 5. Variance analysis for the model of surface roughness

\begin{tabular}{|l|l|l|l|l|}
\hline Parameters & $\begin{array}{l}\text { Sum of } \\
\text { Squares }\end{array}$ & DF & $\begin{array}{l}\mathrm{F} \\
\text { value }\end{array}$ & P value \\
\hline voltage $(S V)$ & 2.83 & 1 & 164.79 & $<0.0001$ \\
\hline Pulse-on time $\left(T_{O N}\right)$ & 0.37 & 1 & 21.79 & 0.0004 \\
\hline Pulse-off time $\left(T_{O F F}\right)$ & 0.082 & 1 & 4.75 & 0.0468 \\
\hline Wire feed rate $(W F)$ & $3.000 \mathrm{E}-004$ & 1 & 0.017 & 0.8968 \\
\hline Quad. $S V(S V \times S V)$ & 0.32 & 1 & 18.64 & 0.0007 \\
\hline Quad. $T_{O N}\left(T_{O N} \times T_{O N}\right)$ & $2.998 \mathrm{E}-003$ & 1 & 0.17 & 0.6825 \\
\hline $\begin{array}{l}\text { Quad. } T_{O F F}\left(T_{O F F} \times\right. \\
\left.T_{O F F}\right)\end{array}$ & $1.411 \mathrm{E}-003$ & 1 & 0.082 & 0.7787 \\
\hline Quad. $W F(W F \times W F)$ & 0.015 & 1 & 0.89 & 0.3621 \\
\hline Interaction $\left(S V \times T_{O N}\right)$ & 0.020 & 1 & 1.14 & 0.3037 \\
\hline Interaction $\left(S V \times T_{O F F}\right)$ & $2.250 \mathrm{E}-004$ & 1 & 0.013 & 0.9105 \\
\hline Interaction $(S V \times W F)$ & 0.12 & 1 & 6.73 & 0.0213 \\
\hline Interaction $\left(T_{O N} \times T_{O F F}\right)$ & 0.011 & 1 & 0.64 & 0.4366 \\
\hline Interaction $\left(T_{O N} \times W F\right)$ & $6.250 \mathrm{E}-004$ & 1 & 0.036 & 0.8515 \\
\hline Interaction $\left(T_{O F F} \times W F\right)$ & 0.024 & 1 & 1.40 & 0.2568 \\
\hline
\end{tabular}

Tab. 6. The effects of voltage, pulse-on time, pulse-off time and wire feed rate on surface roughness

Mathematical model based on RSM correlating process response i.e. surface roughness with various settings of input process parameters during WEDM of $\mathrm{SiC}_{\mathrm{p}} / 6061 \mathrm{Al} \mathrm{MMC}$ have been established, and is represented in the following regression equation. This regression equation is used to determine the optimal values of input process parameters for targeted values of output parameter (i.e. minimum surface roughness in this study).

Surface Roughness $=+7.36240-0.23835 \times V+$ $0.17667 \times T_{O N}-0.041250 \times T_{O F F}+0.67750 \times W F-(3)$
$8.50000 E-003 \times V \times W F+2.16520 E-003 \times V^{2}$

\section{GENETIC ALGORHM}

The genetic algorithm is an evolutionary algorithm that uses genetic operators to obtain optimal solutions without any assumptions about the search space. GA are computerized search and optimization algorithms and work with asset or population of solutions as opposed to traditional optimization techniqueand evolve the set of optimum solution using the principle of natural genetics and natural selection [12].

Genetic algorithm is very efficient stochastic search technique that tries to emulate natural evolution. An important feature of GA is that it searches several paths simultaneously starting with initial population. Each individual element in the population is called a chromosome. Each chromosome can represent a feasible solution containing a sequence/string of binary or real numbers known as genes. During an evolution process, the current population is replaced by a new generation of chromosomes.

The new population may contain both parent chromosomes and newly generated chromosomes called offsprings. Operators like crossover, mutation etc. are used to generate the offspring chromosomes. The crossover operation is a process of merging two parent chromosomes and formation of one or two new chromosomes. Mutation refers to a process of modifying the structure of a selected chromosome by arbitrarily changing one or more genes.

A fitness function representing the objective function is used to evaluate the chromosomes. The chromosomes with high fitness among the parents and offsprings will be selected for the next generation. This process repeats until the satisfaction of the stopping criteria that can be either a limited number of generations are reached or no further improvement in solutions [13].

\subsection{GA based results and analysis}

In the present study, GA is used as an optimization technique for solving a bound-constrained optimization problem. The regression models developed by RSM have been used as objective function and the upper and lower bounds of parameters are identified by conducting experiments. The problem can be formulated as given below. The main aim is to minimize the surface roughness value.

So, the objective functions: Minimize $\mathrm{Z}=\mathrm{W} \times$ (surface roughness) Conversion of multi-objective to single-objective

$\mathrm{W}$ is arbitrarily chosen parameters to represent the importance of each response parameter and taken as 1 .

Subjected to,

$$
\begin{aligned}
& 70 \leq \mathrm{V} \leq 90 \\
& 1 \leq \mathrm{T}_{\mathrm{ON}} \leq 3 \\
& 6 \leq \mathrm{T}_{\mathrm{OFF}} \leq 10 \\
& 5 \leq \mathrm{WF} \leq 9
\end{aligned}
$$

The optimization is carried out in GA Tool box of MATLAB (Version: 7.6.0.324) environment. 
The GA parameters used for parametric optimization are as follows:

Population type: Double vector; Population size: 100; Number of generation: 200; Number of stall generation: 50; Fitness function: Rank scalling; Selection function: Roulette wheel, Crossover function: Two point; Crossover fraction: 0.8; Mutation function: adaptive feasible; Migration: Forward, Migration fraction: 0.2. The plot of fitness value with number of generation is presented in Fig. 2.

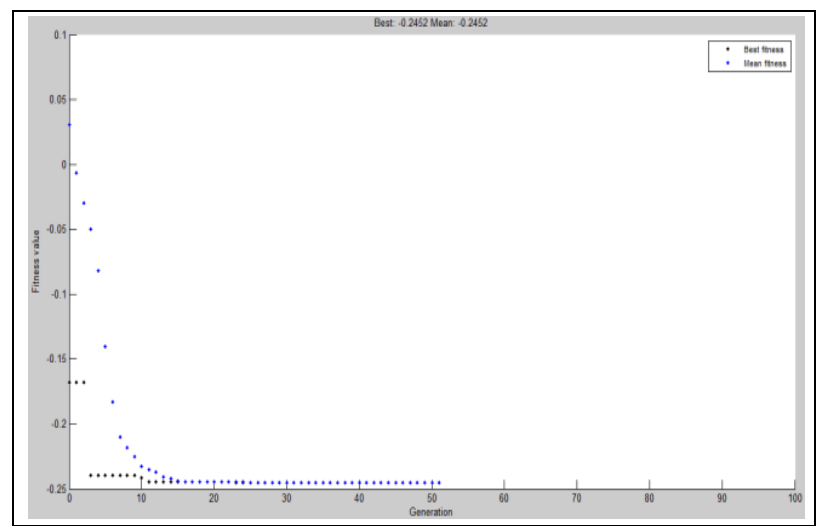

Fig. 2. Plot of fitness value with number of generation

The best (optimum) cutting condition leading to the minimum surface roughness is shown in Table 7. An experiment was carried out at the optimal parametric settings for surface roughness so that targeted value of response parameter can be obtained. Table 7 shows the predicted value of surface roughness obatined from the GA and experimental result with the parameteric optimal setting as obtained from GA. Prediction are in good agreement with the experimental results because the percentage error of the predicted value with respect to the experimentally observed value for surface roughness is not high.

\begin{tabular}{|c|c|c|c|c|c|c|c|}
\hline \multirow{2}{*}{ Response } & \multicolumn{4}{|c|}{$\begin{array}{l}\text { Optimize value of input } \\
\text { parameters }\end{array}$} & \multirow{2}{*}{$\begin{array}{c}\text { Predicted } \\
\text { value } \\
(\mu \mathrm{m})\end{array}$} & \multirow{2}{*}{$\begin{array}{l}\text { Exp } \\
\text { value } \\
(\mu \mathrm{m})\end{array}$} & \multirow{2}{*}{$\begin{array}{l}\% \\
\text { error }\end{array}$} \\
\hline & $S V$ & $T_{O N}$ & $T_{O F F}$ & $W F$ & & & \\
\hline $\begin{array}{c}\text { Surface } \\
\text { Roughness }\end{array}$ & 70 & 3 & 6 & 5 & 1.62 & 1.68 & 3.57 \\
\hline
\end{tabular}

Tab. 7. The optimum values of process parameters

\section{CONCLUSIONS}

In this paper RSM and GA have been used to optimize the process parameters during WEDM of $\mathrm{SiC}_{\mathrm{p}} / 6061 \mathrm{Al}$ MMC. A RSM model was used to develop the relationship between surface roughness and input process parameters. The developed mathematical model was further coupled with a developed GA to find out the optimum conditions leading to the minimum surface roughness value. The predicted optimum cutting condition was validating with an experimental measurement. The maximum percentage absolute error between the experimental value and GA predicted value is $3.57 \%$. This result validates the prediction accuracy of GA, because the maximum percentage absolute error of the predicted value with respect to the experimentally observed value for surface roughness is not high.

The results of the present study based on RSM and GA models can be used for effective and economical machining of MMCs by WEDM process. The present work is focused on the WEDM of $\mathrm{SiC}_{\mathrm{p}} / 6061 \mathrm{Al}$ MMCs having $10 \% \mathrm{SiC}$ particles. In future the study can be extended by using different percentage of SiC particles in MMCs and different work material. Levels of process parameters like wire tension, table feed rate etc. that have been fixed during this study may be varied for further investigations to determine the machinability of MMCs during WEDM process. Similarly, effect of process parameters on other performance measures such as surface integrity aspects and surface texture of machined surface may be investigated.

\section{REFERENCES}

[1] Shandilya, P; Jain, P. K. \& Jain, N. K. (2011). Wire electric discharge machining of metal matrix composites, DAAAM International BOOK 2011, Vol. 10, Chapter 30, pp. 383-400, 9783-901509-84-1

[2] Ho, K.H.; Newman, S.T.; Rahimifard, S., \& Allen, R.D. (2004). State of art in wire electrical discharge machining (WEDM), International Journal of Machine Tools and Manufacturing, Vol. 44, 2004, pp. 1247-1259

[3] Saha, P.; Tarafdar, D.; Pal, S. K.; Srivastava, A.K. and Das, K. (2009). Modeling of wire electro-discharge machining of TiC/Fe in situ metal matrix composite using normalized RBFN with enchanced K-means clustering technique, International Journal of Advanced Manufacturing Technology, Vol. 43, 2009, pp. 107-116

[4] Shandilya, P.; Jain, P. K. and Jain, N. K. (2012). Prediction of Surface Roughness During Wire Electrical Discharge Machining of SiCp/6061 Al MMC, International Journal of Industrial and Systems Engineering, Vol. 12, No. 3, 2012, pp. 301-315

[5] Gao, Q.; Zhang, Q.; Su, S., \& Zhang, J. (2008). Parametric optimization model in electrical discharge machining process, Journal of Zhegiang University Science A, Vol. 9, No. 1, 2008, pp. 104-108

[6] Montgomery D.C. (2001). Design and analysis of experiments, John Wiely and Sons, New York

[7] Rao, S.S. (1991). Optimization theory and Applications, Wiely Eastern Limited, New Delhi

[8] Kuriakose, S; Shunmugam, M.S. (2005). Multi-objective optimization of wire-electro discharge machining processby nondominated sortinggenetic algorithm. Journal of Material Processing Technology, Vol. 170, No. 1-2, 2005, pp. 133-141

[9] Shandilya P.; Jain, N.K. \& Jain, P.K (2011). Experimental studies on WEDC of $\mathrm{SiC}_{\mathrm{p}} / 6061 \mathrm{Al}$ metal matrix composite, Key Engineering Materials, Vol. 450, 2011, pp. 173-176

[10] Myers, R.H. \& Montgomery, D.C. (2002). Response surface methodology: process and product optimization using designed experiments, Second edition, 2002, Wiley, New York

[11] Sameh, S. H. (2009). Study of the parameters in electric discharge machining through response surface methodology approach, Applied mathematical modeling, Vol. 33, 2009, pp. 4397-4407

[12] K. Deb (2000). Multi-objective optimization using evolutionary algorithms, Wiley, Chichester, 2000

[13] Kumar, R. (2010). Comprehensive Design Strategy for a Reconfigurable Manufacturing System, Department of Mechanical \& Industrial Engineering, Indian Institute of Technology Roorkee, India 